\title{
Competency based teaching of college physics: The philosophy and the practice
}

\author{
Ajith Rajapaksha ${ }^{1, *}$ and Andrew S. Hirsch ${ }^{2, \dagger}$ \\ ${ }^{1}$ Purdue Polytechnic Institute, Purdue University, West Lafayette, Indiana 47907, USA \\ ${ }^{2}$ Department of Physics and Astronomy, Purdue University, West Lafayette, Indiana 47907, USA
}

(Received 17 September 2017; published 21 November 2017)

\begin{abstract}
The practice of learning physics contributes to the development of many transdisciplinary skills learners are able to exercise independent of the physics discipline. However, the standard practices of physics instruction do not explicitly include the monitoring or evaluation of these skills. In a competency-based (CB) learning model, the skills (competencies) are clearly defined and evaluated. We envisioned that a CB approach, where the underlying competencies are highlighted within the instructional process, would be more suitable to teaching physics to learners with diversified disciplinary interests. A model CB course curriculum was developed and practiced at Purdue University to teach introductory college physics to learners who were majoring in the technology disciplines. The experiment took place from the spring semester in 2015 until the spring semester in 2017. The practice provided a means to monitor and evaluate a set of developmental transdisciplinary competencies that underlie the learning of force and motion concepts in classical physics. Additionally, the CB practice contributed to produce substantial physics learning outcomes among learners who were underprepared to learn physics in college.
\end{abstract}

DOI: 10.1103/PhysRevPhysEducRes.13.020130

\section{INTRODUCTION}

Competency based $(\mathrm{CB})$ teaching and learning provides learners with expected learning outcomes within a personalized framework [1-4]. Various CB approaches to instruction have been performed in medicine [5,6], psychiatry [7], health care $[8,9]$, and teacher education [10]. However, the $\mathrm{CB}$ approach is yet to be tested in sciences and many applied science (STEM) disciplines. In the STEM disciplines, in contrast to abstract learning of the discipline's content, the CB approach can be used to develop concrete skills (competencies) that are transferable across academic disciplines, or beyond academia to the corporate sector $[11,12]$. Many learners who take introductory level college physics courses may not be using physics concept knowledge directly in their careers. However, the practice of learning physics contributes to the development of many transdisciplinary competencies (TDC) they can exercise independent of the physics discipline [13-16]. We envisioned that a CB approach, where the underlying competencies are highlighted within the instructional process, would be more suitable to teach physics to a group of learners with diversified interests. In January 2015, a model $\mathrm{CB}$ physics course was initiated at Purdue University. To our knowledge, this is the first attempt to use a $\mathrm{CB}$

\footnotetext{
*ajith@purdue.edu

'hirsch@purdue.edu
}

Published by the American Physical Society under the terms of the Creative Commons Attribution 4.0 International license. Further distribution of this work must maintain attribution to the author(s) and the published article's title, journal citation, and DOI. approach to teach physics at a public university in the United States. The CB model that we developed used algebra based methods to synthesize and apply knowledge within force and motion concepts in classical physics. Intradisciplinary practices were mapped into a set of TDC for evaluation. Learners were allowed to use extended time periods to independently develop and to demonstrate the exercise of the TDC. Through this practice we brought up a method to evaluate TDC that underlie the physics disciplinary learning experience. Additionally, the practice consistently contributed to producing substantial physics learning outcomes among learners who were underprepared to learn physics in college.

\section{ORGANIZATION OF THE PAPER}

The paper presents the concept of $\mathrm{CB}$ learning that transcends the boundaries of a classroom, and how this type of learning facilitates the acquisition of TDC. Next, the paper discusses the details of the CB introductory college physics learning experience developed at Purdue University, its outcomes and the implications for physics education in the U.S.

\section{COMPETENCIES: THE IDEA AND APPLICATION}

\section{A. Capability approach vs the human capital theory}

Within a CB instructional process, the valuable practices that transcend a particular learning experience are identified as competencies [3]. The human capital (HC) theory and the capability approach provide contrasting view points on determining the valuable human practices [17] that are 
translated into competencies acquired within a learning process. The HC theory [18-20] values practices that enhance an individual's ability to perform labor and to produce economic capital. The capability approach conceptualized by the Nobel Laureate philosopher Amartya Sen (1998 Noble Prize in Economics) values practices that expand an individual's ability to achieve further excellence [17,21-24]. The HC approach does not take into account the full potential of a human being as opposed to treating an individual as an instrument for the production of capital [25-28]. However, Sen's capabilities idea implies that a curriculum of learning is beneficial to expanding an individual's capacity beyond producing economic capital: "If education makes a person more efficient in commodity production, then this is clearly an enhancement of human capital. This can add to the value of production in the economy and also to the income of the person who has been educated. But even with the same level of income, a person may benefit from education, in reading, communicating, arguing, in being able to choose in a more informed way, in being taken more seriously by others, and so on. The benefits of education, thus, exceeds its role as human capital in commodity production." [23] Not all learners will apply the discipline's content beyond the learning experience. However, all learning processes can contribute to intellectual growth and to increasing the potential for further learning or functioning. Therefore, learning the content of a discipline is better expressed as developing capabilities rather than acquiring directly valuable $\mathrm{HC}$ [17]. Because of this reason, the competencies, or the assessment factors, must be chosen to reflect upon the developmental qualities that transcend the content learning and facilitate further learning or efficient functioning of the learner.

\section{B. Transdisciplinary competencies in learning}

Complying with the capabilities idea (Sec. III A), we chose the following set of developmental qualities as transdisciplinary competencies of the $\mathrm{CB}$ physics learning experience at Purdue University.

(i) AS: Analysis (identification or translation and inference).

(ii) MD: Modeling (knowledge in the appropriate representations and their extensions).

(iii) PS: Problem solving (choice of practices based on the situation and the representation or model).

(iv) CM: Communication (ability to achieve clarity complying to the standards).

(v) CL: Collaboration (contribution to a positive social environment).

(vi) EC: Effective citizenship (commitment and the sense of responsibility about one's own actions).

(vii) AE: Aesthetic engagement (compliance with basic aesthetic rules in presentation of ideas).

These qualities are not limited to the content of any one discipline. They are valued and practiced in all complicated problem solving processes and in cooperative working environments. The first four in the list were regarded as core competencies as they directly associated with learning of the physics disciplinary content.

\section{Practices lead to the TDCs}

Within the context of this paper, the term "practices" refers to various microlevel tasks a learner performs within the process of a particular learning or assessment activity, such as extracting relevant information from a complex situation, drawing vector or force diagrams, creating other illustrations, or making an inference based on a previously achieved result [29]. Exercise of the TDC lies in the practices performed to establish the perception of physics concepts and in the deliberate application of the concepts. Therefore, a CB approach to instruction should focus on the details within the practices in order to provide a scope to exercise and to evaluate the TDC. Concept knowledge is complementary to becoming proficient in the practices performed in the context of the discipline. Mapping the processes in learning or assessment activities appropriately into the underlying competency framework, it is possible to produce a scheme to evaluate the exercise of the core competencies. Other competencies (EC, CL, AE, etc.) can be evaluated through participation, peer evaluations, quality of the individual output and creative group projects.

\section{THE PROCESS (LOGISTICS AND STRUCTURE)}

\section{A. Organization}

At Purdue University, a CB introductory college physics experience was developed for learners who are majoring in technology disciplines [30]. The CB course attempted to match the course requirements of the traditional (T) course serving the same learner community at Purdue University. The $\mathrm{T}$ course used algebra based methods and contained four credit hours, including a laboratory component. The $\mathrm{T}$ course was based on lectures, recitations, and multiple choice examinations. The CB course, on the other hand, facilitated a self-paced learning environment.

The first CB physics course was taught in Spring 2015 to a special cohort recruited to pilot the idea. Since Fall 2015, both methods ( $\mathrm{T}$ and $\mathrm{CB}$ ) were concurrently available for enrollment. At the beginning of a semester, learners could freely enroll in one of the two courses. Table I summarizes the enrollment data for the two classes. Apparently, learners did not make a conscious choice between the two classes. Neither was there an attempt to provide a wide scale awareness on the $\mathrm{CB}$ model course. For most of the learners, the placement in the course had been made by the university scheduling system based on the other classes they had chosen to take.

In the $\mathrm{CB}$ course, the conventional weekly course meeting structure of two $50 \mathrm{~min}$ lectures and one $50 \mathrm{~min}$ recitation were absorbed into two longer (75 min) group working 
TABLE I. The enrollment data for the competency-based (CB) and the traditional $(\mathrm{T})$ classes. The $\mathrm{T}$ course was based on lectures, recitations, and multiple choice examinations. The $\mathrm{CB}$ model provided the scope for individualized learning.

\begin{tabular}{lccccc}
\hline \hline & Spring & Fall & Spring & Fall & Spring \\
Class & 2015 & 2015 & 2016 & 2016 & 2017 \\
\hline $\mathrm{T}$ & 170 & 158 & 143 & 158 & 130 \\
$\mathrm{CB}$ & 10 & 20 & 36 & 60 & 50 \\
\hline \hline
\end{tabular}

sessions designated as "Instructional Studio (IS)." At IS, under the supervision of a primary faculty instructor, undergraduate instructors (UI), preferably, who previously had taken part in the same learning experience, oversaw the learning activities, provided occasional assistance, and performed assessment on the learners. Learners submitted a preclass assignment (PCA) in the evening prior to each IS. The work in an IS was built upon the PCA. Weekly homework (HW) was assigned on the basis of the work done in the IS. Laboratory (LAB) activities were designed to be direct extensions to IS. The course content was organized into content areas. Exercise of the TDC within content areas was assessed using content area tests (CAT). Learners could repeat a CAT up to a period of three weeks. Time and space were made available for learners four days a week to walk in and take or retake a CAT. A CAT was qualitatively similar to the HW. A period of an hour was allowed for each taking of a CAT. Learners could take or retake a CAT by their own initiation with a minimum time separation of three days. Within a given content area, two versions of a CAT were offered to learners. The first version was available for multiple takings. However, the second version was available only for a single attempt per each qualified learner (Sec. IV D).

\section{B. Content knowledge via developing the TDC}

Exercise of the TDC lies in the practices performed in the learning activities. The development of the physics concept knowledge was assumed to be complementary to the development of the TDC (Sec. III C). Therefore, in the CB physics instructional process at Purdue University, the practices were regarded with high importance. Representations of physical phenomenon (vector diagrams, force diagrams, graphs, etc.) were thoroughly exercised, giving importance to fine details within such practices. Learners were expected to communicate their thought processes in completing assignments. Assignment problems deviated from being multiple-choice or direct short-answer questions towards more realistic and rather complicated situations where nontrivial exercise of TDC was possible.

\section{Separating into the TDC}

The TDC were defined in the course syllabus. The practices in learning and assignment activities were mapped into the TDC structure following the definitions. Examples that illustrated the relationship between the standard practices and TDC were supplied live in classes as well as in the reference materials. Rubrics were prepared to enhance the efficiency of assessment and to further communicate the expected outcomes. All course activities, including participation, submission of work, preparation, interaction with peers, etc., were encompassed within the TDC framework and therefore included in assessment. A PCA was not evaluated for accuracy when it explored novel content matter before a class (Table II). However, in a PCA the application of the previously learned practices were evaluated for accuracy. Assessments were done by the personnel who were best suited to evaluating the task. For example, the competency of collaboration was entirely evaluated by peers. The competency of effective citizenship was evaluated by the peers and by the instructors.

\section{Assessment and feedback}

In the $\mathrm{CB}$ instructional process at Purdue University, a continuous and iterative assessment scheme took the place of traditional assessment components such as exams (midterm, final) or homework that bore a prescribed weight in the final grade formula. The continuous assessment scheme encompassed the multitiered process of learning: the construction of knowledge in PCA and in IS, the practice of knowledge in HW, further practice and validation of the establishment of knowledge in CAT. Learners were expected to produce detailed work that communicated the logic and standard practices applied in the assessment activities. This work was evaluated using rubrics within the TDC framework. Formal (written) feedback was provided to learners for PCA, HW, CAT, and LAB. Informal (verbal) feedback was provided during IS and

TABLE II. The CB model course evaluation structure. PCA, HW, CAT, and LAB stand, respectively, for preclass assignments, homework, content area test and laboratory. All assignments were hand graded by multiple instructors following rubrics. GI and UI stand for graduate instructors and undergraduate instructors, respectively.

\begin{tabular}{lcccc}
\hline \hline Category & Correctness & Repeat or Retake option & Feedback provided? & Assessed by \\
\hline PCA & Assessed sometimes & No & Yes & UI \\
HW & Assessed & Yes $(+1)$ & Yes & GI \\
CAT & Assessed & Yes $(+5)$ & Yes & GI \\
LAB & Assessed & No & Yes & GI and UI \\
\hline \hline
\end{tabular}


LAB sessions. In grading CAT, where learners took a single test multiple times, the feedback generation was made efficient by defining error codes for common problematic situations encountered in the activities. Learners were provided with the definitions of the error codes.

The iterative assessment scheme allowed the learners to repeat assessment activities. Successive iterations had to follow the feedback provided by instructors. Table II summarizes the evaluation and feedback process. Learners could use the feedback provided for a HW to make a single resubmission. If the original submission existed, then the resubmitted work was treated for full credit. Taking a CAT was possible up to 6 times within up to three weeks. Each successive iteration of the same CAT had to be spaced out by a minimum period of three days.

\section{E. Content area badges}

Learners who acquired proficiency in exercising the TDC, within the scope set by a smaller area in the content matter, earned a content area badge $(\mathrm{CAB})$. Learners attempted to earn a CAB by taking CAT. A given CAT (CAT X) had two qualitatively similar versions \{CAT X.1, CAT X.2\}. Learners could retake CAT X.1 to enhance their performance outcomes above a prescribed level of $80 \%$. The grading rubrics established that a level of $80 \%$ would account for success in all the assessed concept knowledge and the practices. The scores a learner would earn at a later attempt, regardless of it being higher or lower than the scores of the former attempt, would be registered as the official score for the CAT. A learner who achieved the $80 \%$ level in CAT X.1 was allowed to take the CAT X.2 which was available only for one taking per each qualified learner. A learner who achieved a minimum level of $80 \%$ in CAT X.2 was awarded the particular CAB, and their preliminary scores in HW and PCA within the appropriate content area were replaced with perfect scores, provided that those assignments had been duly submitted. Figure 1 illustrates the practice of a particular learner in the process. The learner started at a poor level (23\%) of proficiency in the practices of the content area, but by the fourth attempt on CAT X.1 demonstrated 97\% proficiency and as a result earned the opportunity to take the CAT X.2. Facing the CAT X. 2 the learner demonstrated $87 \%$ level of proficiency and as a result became entitled to a CAB.

\section{F. Final course grade}

The final course grade in the $\mathrm{CB}$ course was determined based upon a learner being able to concurrently develop all TDC towards prescribed levels. A pass or fail grade would be well suited to the $\mathrm{CB}$ approach because the objective of the $\mathrm{CB}$ learning experience is to make the learner proficient in independently exercising the TDC in their next learning experience or in any other scope for functioning (Sec. III A). Passing a course would have been equivalent to earning an A. However, Purdue University requires

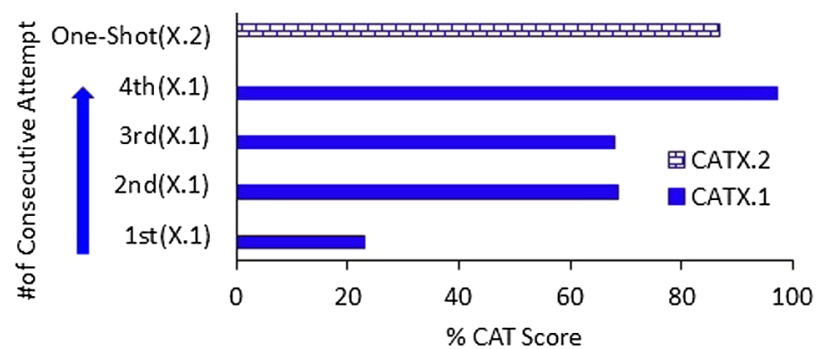

FIG. 1. A learner moving through the process of a content area test (CAT). A given CAT (CAT X) had two versions \{CATX.1, CAT X.2\}. CAT X.1 could be taken up to 6 times, while CAT X.2 was available only for a single taking. The first four horizontal bars (solid) represent four successive attempts of the learner on CAT X.1. The learner starting from a weak base (23\%) has progressed towards a high level of proficiency (97\%) within the CAT X.1, earning the opportunity to take the CAT X.2. The fifth horizontal bar (bricks) represents the outcome of CAT X.2. In CAT X.2, the learner acquired $87 \%$ exercising the single available chance. A proficiency level of $80 \%$ was required for passing a CAT.

letter grades. Therefore, different proficiency levels in TDC were prescribed as requirements for different letter grades (A,B,C,D). The $\mathrm{CB}$ model did not award \pm grades to learners.

\section{RESULTS}

\section{A. Background}

In both classes ( $\mathrm{T}$ and $\mathrm{CB}$ ) the learners were primarily full time college students at the freshman $(\sim \% 40)$ or sophomore ( $\% 50)$ level. Figure 2 summarizes the self reported data, of the learners on their prior to college preparation for taking college physics and their self-efficacy about the subject. The graphs on top and bottom respectively are for the spring and the fall semesters in 2016. The height of the vertical bars indicate the \% learner population that fell into each category $(\mathrm{A}, \mathrm{B}, \mathrm{C})$ listed along the horizontal axis. The $\mathrm{T}$ class is represented by the blue striped columns, while the $\mathrm{CB}$ class is represented by solid red columns. Figure 2 indicates that about $60 \%$ of the learners in both classes either had not had physics prior to college or had low self-efficacy towards learning the subject.

The actual levels of preinstruction preparedness were quantified using a diagnostic force concept inventory (FCI) [31] survey. Figure 3 summarizes the results of this survey for spring (top) and fall (bottom) semesters in 2016. The height of the columns measured along the vertical axes indicate the percent learner population that fell into each percentile group listed along the horizontal axis. The $\mathrm{T}$ class is represented by the blue striped columns, while the $\mathrm{CB}$ class is represented by solid red columns. The results in Fig. 3 show that in both classes $65 \%$ to $70 \%$ of the learners remained in the below $40 \%$ category of the diagnostic FCI score. For the T class, the average diagnostic \% FCI scores respectively were $41.4 \pm 1.6$ and $39.7 \pm 1.9$ for the spring and fall semesters in 2016. In the same respective 

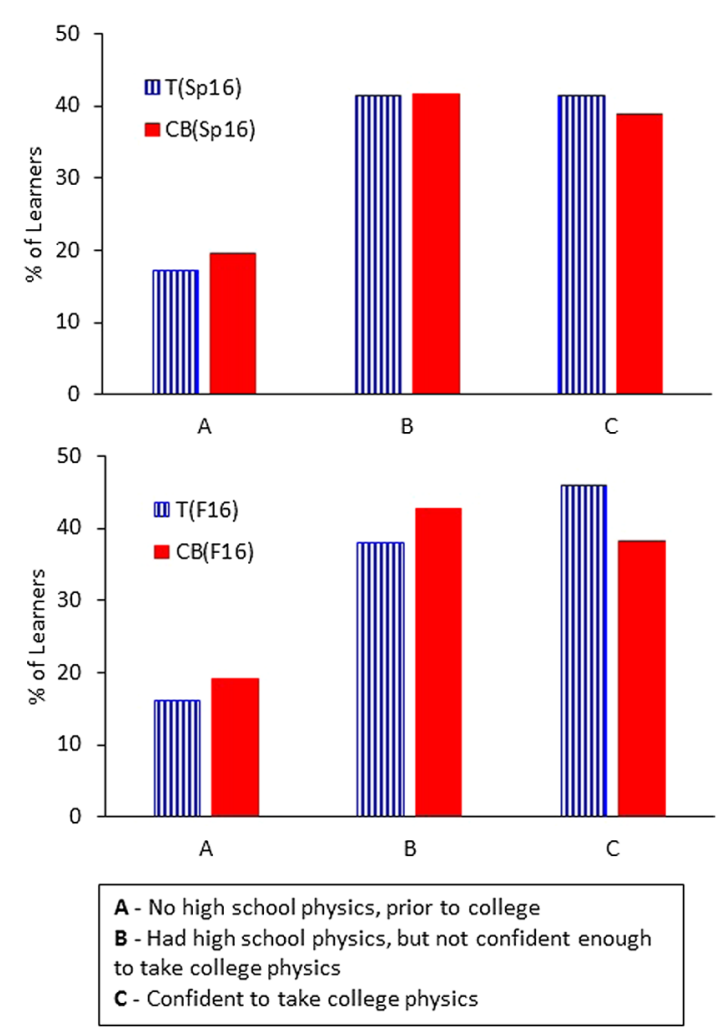

FIG. 2. A background evaluation of the two classes (T and CB) at the beginning of the spring (top) and fall (bottom) semesters in 2016. The height of the vertical bars indicate the $\%$ learner population that chose one of the categories listed along the horizontal axis. The striped columns represent the $\mathrm{T}$ class and the solid columns represent the $\mathrm{CB}$ class. Both classes were similarly populated by learners in terms of their prior to college physics experience and self efficacy towards the college physics learning experience.

semesters, for the CB class, the average diagnostic \% FCI scores were $38 \pm 2.9$ and $36 \pm 1.8$. The $p$ values calculated in MS Excel from standard $t$ tests resulted in 0.32 for spring 2015 and 0.13 for fall 2015 under a $95 \%$ confidence range ( $\alpha=0.05)$ that the null hypothesis is valid. That is, the statistical tests failed to reject that the two learner populations were the same.

A profile of learners' mathematical preparedness was obtained using an in-class survey performed in the spring semester of 2017. The survey investigated how learners felt after learning basic vector methods (vector properties, multiplying a vector by a scalar, addition, subtraction, components) within a module built into the CB physics course. Figure 4 summarizes the outcomes of this survey. Altogether, $90 \%$ of the learners acknowledged it as a helpful experience. $31 \%$ indicated that it was their first time to learn about vectors while $38 \%$ indicated that although they were not novice learners, their knowledge about vectors was found to be similar in levels to that of a beginner. $21 \%$ of the learners acknowledged it as a good review while $10 \%$ indicated that it was not necessary. The results showed that most of the learners were not adequately prepared to learn physics at college.
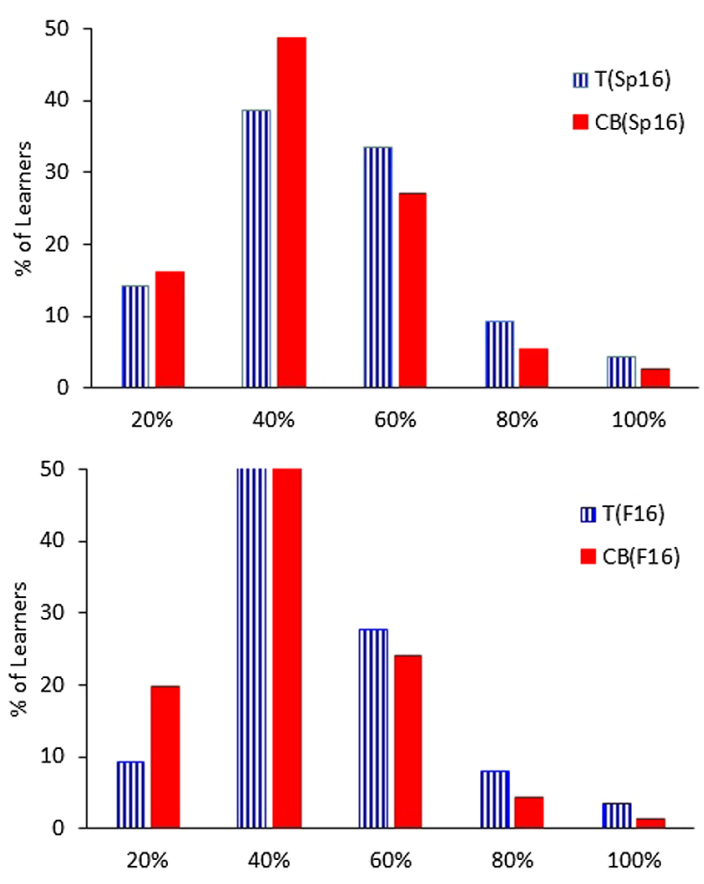

Percentiles are from diagnostic (pre-class) FCl scores

FIG. 3. Distribution of learners of the two classes (T and CB) in terms of their diagnostic FCI scores at the beginning of spring (top) and fall (bottom) semesters in 2016. The height of the vertical bars indicate the percent learner population that fell into each percentile group listed along the horizontal axis. The striped columns represent the $\mathrm{T}$ class and the solid columns represent the CB class. In both classes, $65 \%$ to $70 \%$ of the learners remained in the below $40 \%$ range of the diagnostic FCI score.

\section{B. Postinstructional shifts in physics concept knowledge}

At the end of each semester, the learners in the two classes ( T and $\mathrm{CB}$ ) were evaluated using another FCI test. Figure 5 summarizes the distribution of the learners in the two classes in terms of their FCI scores at the end of the semesters fall 2015 (left), spring 2016 (middle), and fall 2016 (right). The T class is represented by the striped blue columns, while the CB class was represented by solid red columns. The results indicate that in the $\mathrm{T}$ class the learners are concentrated in the below $60 \%$ range and in the $\mathrm{CB}$ class the learners are populated in the above $60 \%$ range. For the $\mathrm{T}$ class in the fall 2015, spring 2016, and fall 2016 semesters, the postinstructional average FCI scores, respectively, were $47.9 \pm 1.6$, $52.6 \pm 1.9$, and $46.6 \pm 1.7$. For the CB class in the same respective semesters, the postinstructional average FCI scores were $69.6 \pm 5,67.3 \pm 3.8$, and $68.1 \pm 2.5$.

\section{Normalized FCI gain}

Using the diagnostic and postinstructional FCI scores, the change in the conceptual understanding due to the instructional process was evaluated in terms of the normalized FCI gain $[32,33](\langle g\rangle$ score), for each semester the CB process took place at Purdue University. The $\langle g\rangle$ score was evaluated using 


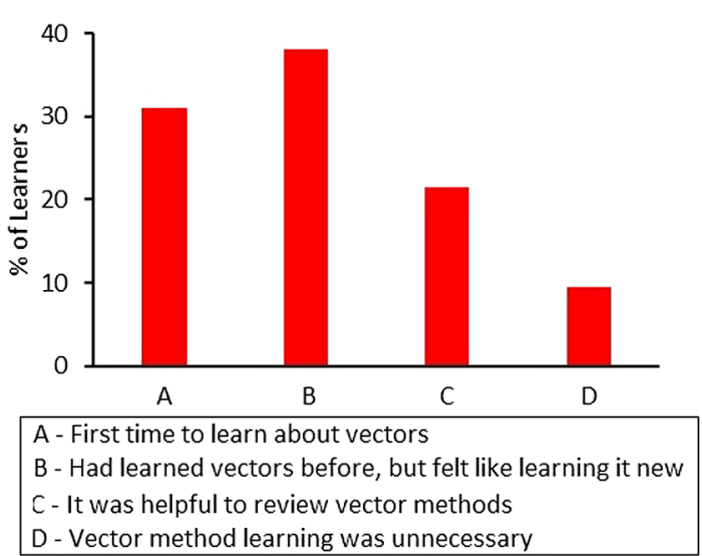

FIG. 4. Learners' opinions about learning basic vector methods in the $\mathrm{CB}$ physics course. The height of the vertical bars are the percent learners who fell into each category listed along the horizontal axis. $31 \%$ of learners claimed it was their first time to learn about vectors, while $38 \%$ claimed that although they were not new to vectors, they felt as if they acquired the knowledge of vectors for the first time. $28 \%$ acknowledged it was a helpful review and $10 \%$ of learners thought it was unnecessary. The results indicate weak mathematical preparation overall to learning physics in college.

$$
\langle g\rangle=\frac{\text { Post } \%-\text { Pre } \%}{100-\text { Pre } \%},
$$

where Pre and Post refer to the diagnostic FCI test and the postinstructional FCI test.

Figure 6 summarizes the $\langle g\rangle$ scores for the five consecutive semesters from spring 2015 through spring 2017. In Fig. 6, the height of the vertical bars indicates the $\langle g\rangle$ score for each semester listed along the horizontal axis. The $\mathrm{T}$ class is represented by the blue striped columns, while the $\mathrm{CB}$ class is represented by solid red columns. As shown in Fig. 6, for the three consecutive semesters from fall 2015 through fall 2016, the $\langle g\rangle$ scores for the CB class is approximately 3 times higher than that for the $\mathrm{T}$ class.

The learners who participated in the CB instructions in the spring semester of 2015 were qualitatively different from the learner groups who participated in the $\mathrm{CB}$ model

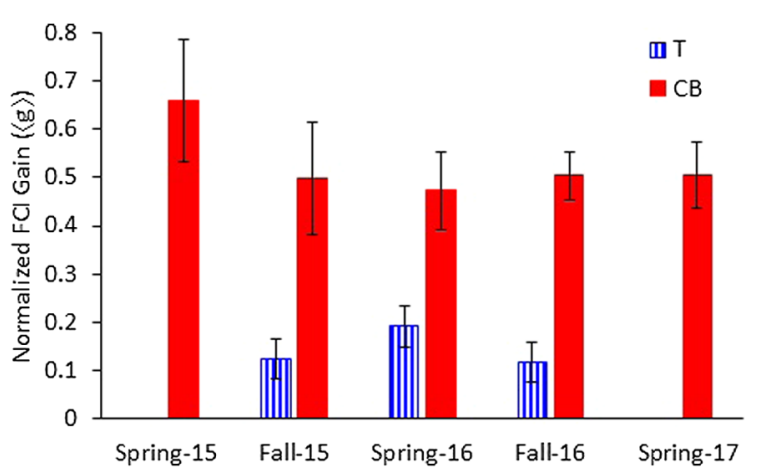

FIG. 6. Comparison of changes to the conceptual understanding due to the instructional process, as measured using the normalized FCI gain $(\langle g\rangle$ score). The height of the vertical bars indicate $\langle g\rangle$ score for each semester listed along the horizontal axis. The striped columns represent the $\mathrm{T}$ class and the solid columns represent the CB class. The $\langle g\rangle$ score of the learners who participated in the CB model instructions are $\sim 3$ times higher than that of the learners who participated in the traditional instructional process.

in other semesters. The spring 2015 group was recruited to pilot the CB model learning idea. First, this group was more aware of the new process than the learners who participated in the other semesters, and they were coached to gain from the CB model. Second, as indicated by their average diagnostic FCI scores $(48.5 \pm 4.8 \%)$, this group on average was better prepared for college physics instruction compared to the other groups.

The uncertainties shown along with the average FCI scores are the standard error of the mean. The error bars for normalized gain were estimated by propagating the standard error.

\section{Development of the TDC in CB learning}

In the CB course, TDC were evaluated within content areas (Sec. IV D). Table III summarizes the class average percent scores in the core competencies (AS,MD,PS,CM) obtained in CAT over three consecutive content ares (force, laws of motion, and circular motion) in the fall 2016. The
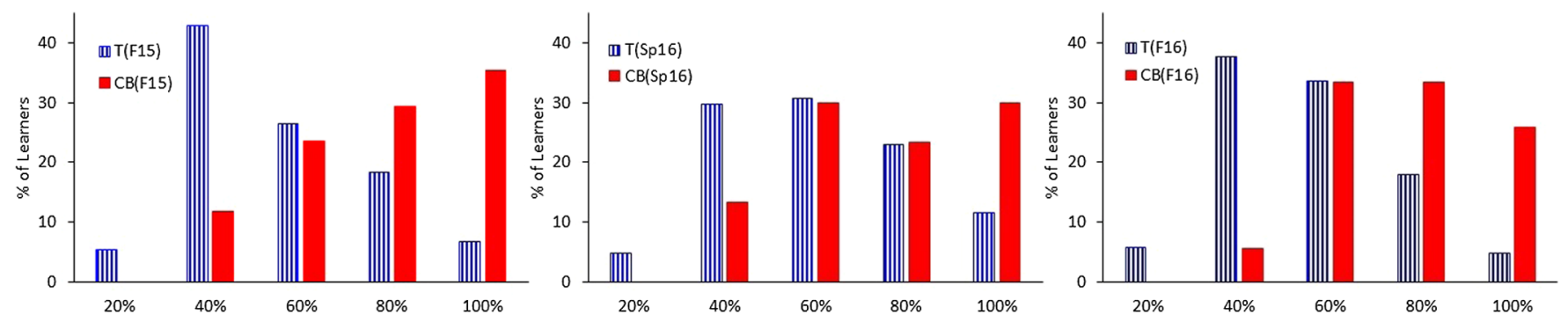

FIG. 5. Distribution of learners of the two classes (T and CB) in terms of the post instructional FCI scores at the end of fall 2015 (left), spring 2016 (middle), and fall 2016 (right) semesters. The height of the vertical bars indicate the percent learner population that fell into each percentile group listed along the horizontal axis. The striped columns represent the T class and the solid columns represent the CB class. Unlike at the diagnostic survey (Fig. 3), the learners in the two classes demonstrate distinctly different distributions at the end of the learning process. In the $\mathrm{T}$ class, the learners are concentrated in the below $60 \%$ range and in the $\mathrm{CB}$ class the learners are populated in the above $60 \%$ range. 
TABLE III. Class average percent scores in core competencies (AS,MD,PS,CM) at the beginning (first four columns) and at the end (last four columns) of CAT for three successive content areas in the spring 2017 semester for the CB class. In each successive content area, learners achieved a higher score in each competency at their first attempt of the CAT than they had in the former content area. Also, in all the competencies the class's average scores improved over the period a CAT was available for retaking.

\begin{tabular}{|c|c|c|c|c|c|c|c|c|}
\hline \multirow[b]{2}{*}{ Content area } & \multicolumn{4}{|c|}{ CAT first attempt $\%$} & \multicolumn{4}{|c|}{ CAT final $\%$} \\
\hline & AS & MD & PS & $\mathrm{CM}$ & AS & MD & PS & $\mathrm{CM}$ \\
\hline Force & 34.1 & 35.0 & 26.4 & 48.6 & 77.0 & 72.9 & 65.3 & 76.6 \\
\hline Laws of motion & 43.4 & 48.1 & 37.0 & 99.8 & 73.2 & 79.2 & 70.7 & 99.9 \\
\hline Circular motion & 68.9 & 65.6 & 59.5 & 98.3 & 82.4 & 82.4 & 79.7 & 98.4 \\
\hline
\end{tabular}

first four columns list the scores acquired at learners' first attempt on a CAT and the last four columns list the scores acquired by the end of the period of each CAT. The scores indicate that in each successive content area at their first attempt on a CAT, learners acquired a higher score in each competency than they had in the former content area. Also, in all the competencies, the class's average scores improved over the period a CAT was available for retaking.

\section{DISCUSSION}

\section{A. An overview}

A CB approach to teaching and learning physics was developed and tested for learners majoring in technology disciplines at Purdue University [30]. The goal of the practice was to implement a method to evaluate the transdisciplinary competencies (TDC) that underlie the learning of physics disciplinary content. This goal was achieved by mapping the processes in learning activities onto a set of TDC (Sec. III B and Sec. VD). Also, through the CB practice, it was possible to consistently observe substantial physics learning outcomes from learners who were mostly underprepared to learn physics in college and had low selfefficacy towards the subject (Sec. V B).

\section{B. The essential features of a $\mathrm{CB}$ instructional process}

We believe the following features are essential for a $\mathrm{CB}$ learning experience:

(i) The competencies must be highlighted and evaluated within a CB instructional process. The discipline's content knowledge is complementary to the development of the competencies.

(ii) An iterative assessment scheme is essential for $\mathrm{CB}$ instruction. It is not reasonable nor realistic to expect an apprentice to develop expert skills of a trade without allowing time for such development. An iterative assessment process provides learners the opportunity to develop, while allowing the instructors the opportunity to guide.

\section{Choice of the TDC}

In the $\mathrm{CB}$ physics instructional process at Purdue University, the choice of the TDC was made based on Amartya Sen's capability idea (Sec III A). The set of TDC
(Sec. III B) represents qualities that are developmental and measurable across disciplines. The core competencies (AS, $\mathrm{MD}, \mathrm{PS}, \mathrm{CM}$ ) were chosen observing the nature of the practices emphasized by physics educators for the process of applying physics concepts to natural phenomena. Most introductory physics textbooks carry a section at the beginning on this behalf [34-36]. This procedure (analysis, modeling, making predictions through standard protocols applied to the model, and communication) is common to any discipline that develops and maintains formal disciplinary knowledge aiming to apply such knowledge to situations specific to the domain. Therefore, the same core competencies can be used across the various disciplines. The CL (collaboration) competency was chosen to promote harmony and solidarity within the instructional environment. The EC (effective citizenship) competency was chosen to promote ethical practices that benefit a learner towards progressing in the course, while creating a sense of commitment and responsibility. Finally, the AE (aesthetic engagement) competency was chosen in order to invoke creativity among learners and to demonstrate the potential to incorporate physics conceptual ideas within aesthetic products. In the future we plan to collaborate with other disciplinary courses to investigate if the chosen set of TDC is complete and sufficient for transdisciplinary application.

\section{Benefit of highlighting the TDC}

Introductory college physics courses in the US are mostly populated with learners who are majoring in disciplines other than physics [14]. Most of them major in various applied science disciplines (engineering, technology, life sciences, health sciences, etc.). Such learners do not essentially use a majority of physics concepts in their own disciplinary studies or in their professions. After all, in their own disciplinary courses they learn the physics formula that is applied within their confined domain. Educators envision the introductory physics learning experience to provide life long competencies in problem solving and critical thinking $[13,14]$. However, most of the time, learners deal with their introductory physics requirement merely as a way of fulfilling an institutional requirement without attributing a long-term value to their learning process [37-39]. This attitude is detrimental to the learning as cognitive goals cannot be fulfilled without true participation of the learner [40-42]. If the introductory 
physics learning experience is staged, bringing the underlying TDC explicitly to light, learners will be able to recognize the broad importance of their physics learning experience.

In the $\mathrm{CB}$ course the TDC were evaluated by mapping the intradisciplinary practices into the TDC framework (Sec. III C). The practices used to learn and apply the physics concepts are common to all content areas within the discipline of physics. Therefore, when repeatedly shown the use, learners acquire the ability to independently exercise these standard practices. The results summarized in Table III show that when learners move from one content area to another, their aptitude for exercising the TDC in the first attempt of a CAT has increased (see the learner comment at the end of Sec. VIE).

\section{E. $\langle g\rangle$ Score and contemporary pedagogies}

The CB model instructional process at Purdue University focused on evaluating the exercise of the TDC that underlie the learning and applying physics concepts. The process emphasized quality in the practices (Sec. III C) and allowed repetition (Sec. IV D) in order for learners to become familiar with exercising the TDC. During this process learners critically engaged their physics and mathematical knowledge. The physics concept understanding acquired by qualitatively similar learner groups (Figs. 2 and 3) through CB model and traditional instructional practices were compared using FCI and the normalized FCI gain $[32,33](\langle g\rangle)$ measurements (Fig 6). At all the stages of the practice, the learners who participated in the $\mathrm{CB}$ model outperformed the traditional learners by a factor of 3 or more in the $\langle g\rangle$ (Fig. 6).

Table IV summarizes the FCI and $\langle g\rangle$ measurements for the $\mathrm{CB}$ practice alongside other pedagogical approaches reported in the literature. These data indicate that the $\langle g\rangle$ scores of the CB model is comparable to that of the other methods. Some pedagogical approaches to teaching physics focus on the development of the content matter knowledge through various engaging methods [43-49]. Some other

TABLE IV. Summary of FCI measurements for different pedagogical practices. Despite catering to learners showing a lower initial level aptitude (see Pretest \%), the $\langle g\rangle$ of the CB model is comparable to other pedagogical practices performed for advance learners in calculus based streams with higher initial level aptitudes.

\begin{tabular}{|c|c|c|c|c|c|c|c|}
\hline Practice & Institute & Group & Year & Pretest $\%$ & Post-test $\%$ & Change $^{a}$ & $\langle g\rangle$ \\
\hline \multirow[t]{8}{*}{ Peer Instruction [43] } & Harvard University & Calculus base & 1991 & 71 & 85 & 14 & 0.49 \\
\hline & & & 1993 & 70 & 86 & 16 & 0.55 \\
\hline & & & 1994 & 70 & 88 & 18 & 0.59 \\
\hline & & & 1995 & 67 & 88 & 21 & 0.64 \\
\hline & & & 1996 & 67 & 89 & 22 & 0.68 \\
\hline & & & 1997 & 67 & 92 & 25 & 0.74 \\
\hline & & Algebra based & 1998 & 50 & 83 & 33 & 0.65 \\
\hline & & & 2000 & 47 & 80 & 33 & 0.63 \\
\hline Studio physics [44] & $\begin{array}{l}\text { Rensselaer } \\
\text { Polytechnic }\end{array}$ & Calculus base & 1999 & 49.8 & 69.4 & 19.6 & 0.20 \\
\hline Studio + ILD $^{c}$ & & & 1999 & 50.4 & 68.1 & 17.7 & 0.36 \\
\hline Studio + ILD + CGPS ${ }^{d}$ & & & 1999 & 50.1 & 66.8 & 16.7 & 0.33 \\
\hline \multirow[t]{2}{*}{ ISLE $[50]^{\mathrm{e}}$} & Ohio State University & $\begin{array}{l}\text { Calculus base } \\
\text { (engineering honors) }\end{array}$ & 2001 & & & & 0.56 \\
\hline & $\begin{array}{l}\text { California State } \\
\text { University, Chico }\end{array}$ & Calculus base & 2001 & & & & 0.45 \\
\hline \multirow[t]{5}{*}{ Competency Based (CB) } & Purdue University & $\begin{array}{l}\text { Algebra based } \\
\text { (technology majors) }\end{array}$ & 2015 Spring & 48.5 & 82.4 & 33.9 & 0.66 \\
\hline & & & 2015 Fall & 39.4 & 69.6 & 30.2 & 0.50 \\
\hline & & & 2016 Spring & 38 & 67.4 & 29.3 & 0.47 \\
\hline & & & 2016 Fall & 35.7 & 68.1 & 32.4 & 0.50 \\
\hline & & & 2017 Spring & 36.4 & 68.5 & 32.1 & 0.50 \\
\hline \multirow[t]{3}{*}{ Traditional Lectures } & Purdue University & $\begin{array}{l}\text { Algebra based } \\
\text { (technology majors) }\end{array}$ & 2015 Fall & 40.5 & 47.9 & 7.3 & 0.12 \\
\hline & & & 2016 Spring & 41.4 & 52.6 & 11.3 & 0.19 \\
\hline & & & 2016 Fall & 39.7 & 46.8 & 7.1 & 0.12 \\
\hline
\end{tabular}

${ }^{\mathrm{a} C h a n g e}=$ Pretest $\%$-Post-test $\%$

${ }^{\mathrm{b}}$ Rensselaer Polytechnic Institute.

${ }^{\mathrm{c}}$ Interactive lecture demonstrations [44].

${ }^{\mathrm{d}}$ Cooperative group problem solving [44].

${ }^{\mathrm{e}}$ Investigative science learning experience. 
approaches such as ISLE [50,51] focus on the development of scientific abilities. On the other hand, the CB approach practiced at Purdue University followed the capability idea [17,21-23] (Sec. III A) and focused on the developmental TDC that underlie the learning and applying of physics concepts. The CB approach emphasized the quality of the practices performed in learning activities and allowed an extended scope for learners to develop in TDC at a relatively self-driven pace. The learners who were catered by the $\mathrm{CB}$ instructional process were mostly underprepared or had low self-efficacy towards the subject (Figs. 2, 3, and 4). However, via the CB model instructions these learners consistently demonstrated $\langle g\rangle$ that is comparable to their advanced counterparts in calculus based streams with better initial level aptitudes (Table IV). We believe this performance is due to the emphasis on the practices and the iterative nature in the assessment process which are essential features of a CB approach (Sec. VI B). The emphasis on the practices required the learners to critically engage in their learning and assessment activities to gain insight that the standard practices can be used to navigate through complicated investigations. The iterative assessment scheme (Sec. IV D and Table II) provided the learners an extended scope to develop in the practices (Fig. 1). Subsequently, learners grew in their physics conceptual understanding [40,52]. As one learner wrote in a feedback survey following the Fall 2016 course, "I learned how to problem solve, when I could not do something, or the answer was not right in front of me I learned how to solve it. I learned that physics is not just equations and can relate to everyday life. I learned how to be persistent and how important it is to keep learning and keep trying".

\section{F. Adopting and extending the CB model}

The procedures reported in this article were performed for classes ranging up to 60 learners. It is estimated that the current version of the $\mathrm{CB}$ model can directly be scaled up for classes of 100 to 120 learners in a session. We believe the modification suggested in the future work (Sec. VIII), to adopt an optimized self-paced learning environment with unstructured class sessions, is useful for scaling up the CB instructional model for moderate to large enrollment courses (200 to 300 learners in a session).

The AE (aesthetic engagement) competency aimed to bring creativity and aesthetics meaningfully into the process of physics learning. In the CB course, learners were given the opportunity to work on a project themed physics story telling where they developed a story that was narrated using the principles learned in the course. Such projects could be used to interface a physics course with liberal arts courses such as languages, writing, poetry, theater, etc., or even with courses such as computer graphics and animations. A physics course can be interfaced with mathematics courses or other STEM courses within the TDC framework (Sec. VI C). In the future, we intend to work further on this idea to experiment how different disciplinary courses could complement each other within a common TDC framework.

Since the dynamics of the CB instructional model is different from the majority of college courses, learners may demonstrate lack of understanding regarding how the $\mathrm{CB}$ course is conducted. As a remedy to this issue, the $\mathrm{CB}$ course introduced a mandatory syllabus quiz at the beginning of the semester to ensure that the learners would understand the course model and adjust to its dynamics. The scores of the quiz were absorbed into the EC (effective citizenship) competency.

Separate evaluation of each competency was an important feature of the CB instructional process at Purdue University. The course grade was based upon the levels reached in each competency, rather than on a cumulative course score. We required this to nurture well-rounded learners as some competencies can be more easily attained than others (Table III), but all competencies are equally important for learning and for functioning beyond the learning.

\section{CONCLUSIONS}

The competency based approach to teaching and learning is regarded as a method that better communicates to learners the expected outcomes of their learning experiences [1-3]. Various CB approaches have been successfully practiced in training professionals in health care and medicine [5,7-9] and in teacher education [10]. We envisioned that a CB approach, where the underlying competencies were highlighted within the instructional process, would be effective to teaching physics to learners with diversified disciplinary interests. At Purdue University, a CB model was developed and practiced to facilitate introductory college physics instruction within the force and motion concepts of classical physics. In this practice, the capability idea [17,21-23] (Sec. III) was chosen to be the philosophical foundation for identifying competencies within the physics learning experience. Following the capabilities idea a set of developmental qualities were chosen to be the transdisciplinary competencies of the learning experience. Intradisciplinary practices were mapped into the TDC for assessment. Learners were allowed to use extended time periods to develop in TDC through an iterative assessment scheme. To our knowledge, this is the first attempt to use a $\mathrm{CB}$ approach to teach physics at a public university in the United States. The CB model practiced at Purdue University provided a means to evaluate a set of TDC that underlie the learning and application of the concepts in physics. Additionally, the CB practice consistently showed its ability to assist learners who were underprepared to learn college physics and had low self efficacy towards the subject to earn substantial physics learning outcomes.

\section{FUTURE WORK}

The CB model physics instructional process developed at Purdue University featured a self-paced learning environment. We believe further optimization of this feature 
within the $\mathrm{CB}$ approach would efficiently accommodate the diversity among learners in prior knowledge levels and different levels of commitment towards completing learning activities. We aim to achieve this by facilitating an unstructured learning space where learners will work independently, work with peers, or seek guidance from instructors to complete the pre-assessment learning activities. At this stage, it will not be possible to have organized class sessions rather than providing a space and time for assembly. The participation of learners in such rather informal course meetings may be based on their individualized purposes. Learners would participate seeking consultation, approval or assistance. In order for such a practice to be successful, the outline of the learning activities must be prepared, perhaps in the form of a workbook, and supportive instructional materials such as video tutorials, sample problem solutions and detailed rubrics be made available for learners. The sessions will be the quality assessment points for learners who are leading in the process while the learners who are lagging in the process can work under the guidance of their peers, whose successful progress has been checked and verified by the instructors.

We intend to use the above modification to scale up the CB instructional model for moderate to large enrollment courses (150 to 300 learners in a session). This expansion is expected to be achieved by absorbing the traditional class into the CB instruction (Table I). In a moderate to large enrollment setting, it may be challenging to maintain a central pace for $\mathrm{CB}$ class sessions without substantial instructor resources. However, when the class sessions are unstructured and entirely self-paced, learners could team up with peers based on their learning requirements. The guidelines for preassessment learning activities will be provided and supplementary instructional material will be made accessible to learners. The self-sufficient and the leading learners will be made pro tem instructors to help those who need more assistance. Peer instructional collaborations will be rewarded through CL (collaboration) and EC (effective citizenship) competencies. Subjected to this practice, learners are likely to feel that the course is directly catering to their individual learning needs rather than being forced to move forward at a pace dictated by an instructor or by their high performing peers. In the future, we intend to provide a detailed report of this procedure.

\section{ACKNOWLEDGMENTS}

The authors acknowledge the support from Professor John P. Finley, the chair, and the staff, of the Department of Physics and Astronomy at Purdue University in making the CB experiment for teaching college physics sustainable. Also, the authors express gratitude to the Dean of Technology (Purdue Polytechnic Institute) Gary R. Bertoline and the Interim Associate Dean Jeffrey J. Evans for allocating the infrastructure for the experiment. A. R. recognizes with great appreciation the contribution of Jeremy Munsell, Ben Cruz,
Joe Zweng, Jesse Ickes, Megan Harwell, Nathan Shrum, Jared Rassbach, Elizabeth Cauffiel, Emily Tluangneh, Mariah Mathews, Nigel Wilson, Dallas Heil, Amandeep Bakshi, and Sreyansh Agrawal who served as instructors (teaching assistants) in the CB model course. A. R. acknowledges with great respect the insightful guidance received from his mentors; Dr. Brian A. Todd, former faculty at Department of Physics and Astronomy at Purdue University, and Professor Leonard Harris of the Department of Philosophy at Purdue University, in the organization of the article.

\section{APPENDIX: LEARNER COMMENTS}

Learners' comments on what they thought were the beneficial traits acquired due to the $\mathrm{CB}$ course reflected mostly on the ability to independently deal with concepts and complex problems. The comments were made anonymously via the end of semester surveys. Samples of nonduplicating comments are listed below. The comments are left in their original format without editing for spelling or grammatical errors.

(i) I learned how to think about a problem critically, it is much easier to break down and work out problems even not related to physics (Sp17).

(ii) I feel that I understand why physics equations are the way they are as opposed to just plugging in numbers (Sp17).

(iii) The class helped me to apply the concepts of physics into my lesson plans as a flight instructor. I put Newton's laws into those lesson plans so I can teach my students these concepts (Sp17).

(iv) I learned that solutions to situations can be thought about and approached in many different ways (Sp17).

(v) Learned how to learn independently (Sp17).

(vi) Working out all the steps to a problem is very important, you might know the correct answer but if you don't know the steps to get there its useless (Sp17).

(vii) I liked when we derived equations, it got me thinking about equations in other classes (Fall16).

(viii) I understood that every concept in the course is useful for the next section. I understood that physics simply is not a math course, you must apply equations and concepts (Fall16).

(ix) Vectors. Last year I took a statics class and ended up dropping due to lack of knowledge about vectors and was struggling a lot. If I had known this much about vectors then, I probably would have continued and passed the class (Fall16).

(x) The force diagrams are prime examples of concepts that are not performing mathematical processes. You actually had to understand physical properties to accurately fill out a force diagram, and without it, solving most problems was not possible (Fall16).

(xi) The class required students to learn/practice time management and communication (Fall16). 
[1] R. A. Voorhees, Competency based learning models: A necessary future, New Directions Institutional Res. 2001, 5 (2001).

[2] U.S. Department of Education, Competency-based learning or personalized learning, https://www.ed.gov/oii-news/ competency-based-learning-or-personalized-learning.

[3] J. M. Palardy and J. E. Eisele, Competency based education, The Clearing House: A Journal of Educational Strategies, Issues and Ideas 46, 545 (1972).

[4] J. R. Harden, M. H. Crosby, M. Davis, and R. M. Friedman, AMEE guide no. 14: Outcome-based education: Part 5-from competency to meta-competency: a model for the specification of learning outcomes, Med. Teach. 21, 546 (1999).

[5] D. V. Muttuvelu and C. U. Anderson, Cataract surgery education in member countries of the european board of ophthalmology, Canadian Journal of ophthalmology 51, 207 (2016).

[6] W. C. Leung and V. Diwakar, Learning in practicecompetency based medical training: reviewcommentary: The baby is thrown out with the bathwater, Br. Med. J. 325, 693 (2002).

[7] C. Jordan and A. Kassam, Mentorship for residents in psychiatry: a competency-based medical education perspective with career counseling tools, Academic Psychiatry 40, 441 (2016).

[8] K. W. Rugen, E. Speroff, S. A. Zapatka, and R. Brienza, Veterans affairs interprofessional nurse practitioner residency in primary care: A competency-based program, Journal of the American Academy of Nurse Practitioners 12, e267 (2016).

[9] D. D. S. Tilley, Competency in nursing: A concept analysis, J. Contin. Educ. Nurs. 39, 58 (2008).

[10] K. M. Zeichner, Alternative paradigms of teacher education, J. Teach. Educ. 34, 3 (1983).

[11] R. W. Burns and J. L. Klingstedt, Competency Based Education, an Introduction (Education Technology Publications, Englewood Cliffs, NJ, 1973).

[12] J. W. Burke, Competency Based Education and Training (The Falmer Press, Taylor \& Francis Inc., Bristol, PA, 1990).

[13] N. R. Council et al., Education for Life and Work: Developing Transferable Knowledge and Skills in the 21st Century (National Academies Press, Washington, DC, 2013).

[14] D. J. Grayson, Rethinking the content of physics courses, Phys. Today 59, No. 2, 31 (2006).

[15] E. Politsinsky, L. Demenkova, and O. Medvedev, Ways of students training aimed at analytical skills development while solving learning tasks, Procedia-Social Behav. Sci. 206, 383 (2015).

[16] D. Craciun, M. Oprescu, and F. Oprescu, Pre-service teacher training of romanian students in english and physics from an inter-, pluri-, transdisciplinary perspective, J. Educ. Sci. Psychol. 3, 1 (2013).

[17] I. Robeyns, Three models of education: Rights, capabilities and human capital, School Field 4, 69 (2006).

[18] A. Duncan, Improving human capital in a competitive world-education reform in the U.S.: https://www.ed.gov/ news/speeches/improving-human-capital-competitive-worldeducation-reform-us, (2011), secretary Arne Duncan's
Remarks at the World Bank, Human Development Network Forum.

[19] S. Burgess, Human capital and education: The state of the art in the economics of education, Institute for the Study of Labor (IZA) Discussion Paper (2016), https://papers.ssrn .com/sol3/papers.cfm?abstract_id=2769193.

[20] G. S. Becker, Human Capital: A Theoretical and Empirical Analysis, with Special Reference to Education (University of Chicago Press, Chicago, IL, 2009).

[21] A. Sen, Equality of what?, in The Tanner Lecture on Human Values (Cambridge University Press, Cambridge, 1980), Vol. 1.

[22] A. Sen, Inequality Re-examined (Clarendon Press, United Kingdom, 1992).

[23] A. Sen, Human capital and human capability, World development, 25, 1959 (1997).

[24] S. Anand and A. Sen, Concepts of human development and poverty: A multidimensional perspective, in Poverty and Human Development: Human Development Papers 1997 (United Nations Development Programme, New York, 1997), pp. 1-20.

[25] M. Woodhall, Human capital: educational aspects, in International Encyclopedia of the Social \& Behavioral Sciences (Elsevier Ltd., New York, 2001), p. 6951-6955.

[26] S. Chattopadhyay, A critique of the human capital theory, in Education and Economics (Oxford University Press, New York, 2012).

[27] M. H. Strober, Human capital theory: Implications for HR managers, Industrial relations 29, 214 (1990).

[28] R. Ralph, G. Rees, and S. Gorard, Some sociological alternatives to human capital theory and their implications for research on post-compulsory education and training, J. Educ. Work 12, 117 (1999).

[29] D. Hestenes, Toward a modeling theory of physics instruction, Am. J. Phys. 55, 440 (1987).

[30] https://polytechnic.purdue.edu/departments (2017).

[31] D. Hestenes, M. Wells, and G. Swackhamer, Force Concept Inventory, Phys. Teach. 30, 141 (1992).

[32] R. R. Hake, Interactive-engagement versus traditional methods: A six-thousand-student survey of mechanics test data for introductory physics courses, Am. J. Phys. 66, 64 (1998).

[33] V. Coletta and J.A. Phillips, Interpreting FCI scores: Normalized gain, preinstruction scores, and scientific reasoning ability, Am. J. Phys. 73, 1172 (2005).

[34] E. Mazur, Principles and Practices of Physics (Pearson Educ., Upper Saddle River, NJ, 2015).

[35] D. M. Katz, Physics for Scientists and Engineers: Foundations and Connections with Modern Physics (Cengage Learning, Boston, 2015).

[36] E. Etkina, M. Gentile, and A. Van Heuvelen, College Physics (Pearson Educ., Upper Saddle River, NJ, 2014).

[37] H. Lin, Learning physics vs. passing courses, Phys. Teach. 20, 151 (1982).

[38] G. Kortemeyer, The challenge of teaching introductory physics to premedical students, Phys. Teach. 45, 552 (2007).

[39] L. Kirkup, D. Scott, and M. Sharma, Teaching physics to non-physics majors: models extant in australian universities, in Proceedings of The Australian Conference on Science and Mathematics Education (formerly UniServe Science Conference) (University of Sidney, Sydney, 2012), 
https://openjournals.library.sydney.edu.au/index.php/IISME/ article/view/6343.

[40] T. Doyle and T. Zakrajsek, The New Science of Learning, 1st ed. (Stylus Publishing, Sterling, VA, 2013).

[41] R. K. Sawyer, The Cambridge Handbook of the Learning Sciences (Cambridge University Press, Cambridge, England, 2005).

[42] J. J. Ratey, A User Guide to the Brain: Perception, Attention, and the Four Theaters of the Brain (Lawrence Erlbaum Assoc., Inc. Pub., Mahwah, NJ, 2001).

[43] C. H. Crouch and E. Mazur, Peer instruction: Ten years of experience and results, Am. J. Phys. 69, 970 (2001).

[44] K. Cummings, J. Marx, R. Thornton, and D. Kuhl, Evaluating innovation in studio physics, Am. J. Phys. 67, S38 (1999).

[45] L. C. McDermott, P. S. Shaffer, and C. P. Constantinou, Preparing teachers to teach physics and physical science by inquiry, Phys. Educ. 35, 411 (2000).

[46] K. Perkins, W. Adams, M. Dubson, N. Finkelstein, S. Reid, C. Wieman, and R. LeMaster, Phet: Interactive simulations for teaching and learning physics, Phys. Teach. 44, 18 (2006).

[47] R. J. Beichner, J. M. Saul, D. S. Abbott, J. J. Morse, D. Deardorff, R. J. Allain, S. W. Bonham, M. H. Dancy, and J. S. Risley, The student-centered activities for large enrollment undergraduate programs (scale-up) project, Research-Based Reform of University Physics 1, 2 (2007).

[48] E. Etkina, A. Karelina, M. Ruibal-Villasenor, D. Rosengrant, R. Jordan, and C. E. Hmelo-Silver, Design and reflection help students develop scientific abilities: Learning in introductory physics laboratories, J. Learn. Sci. 19, 54 (2010).

[49] E. Etkina, A. Van-Heuvelen, S. White-Brahmia, D. T. Brookes, M. Gentile, S. Murthy, D. Rosengrant, and A. Warren, Scientific abilities and their assessment, Phys. Rev. ST Phys. Educ. Res. 2, 020103 (2006).

[50] E. Etkina and A. Van-Heuvelen, Investigative science learning environment: Using the processes of science and cognitive strategies to learn physics (2001), https:// www.compadre.org/repository/document/ServeFile.cfm? $\mathrm{ID}=4379 \& \mathrm{DocID}=1021$.

[51] E. Etkina and A. Van Heuvelen, Investigative science learning environment-a science process approach to learning physics, Research-Based Reform of University Physics 1 (2007).

[52] P. I. Pavlik and J. R. Anderson, Using a model to compute the optimal schedule of practice, J. Exper. Psychol. 14, 101 (2008). 